\title{
Quantitation of Immunocompetence in Hodgkin's Disease
}

\author{
Guy B. FAguet \\ From the Department of Medicine, Medical College of Georgia, \\ Augusta, Georgia 30902
}

A B S T R A C T In vitro cellular immunocompetence was investigated on 35 patients with Hodgkin's disease by studying their in vitro lymphocyte responsiveness to full range stimulation achieved by a spectrum of phytohemagglutinin concentrations. When compared to the normal lymphocyte profile elicited from 35 control subjects, the Hodgkin's patterns of response enabled the identification of a quantifiable lymphocyte defect present in most patients regardless of their clinical status. Increasing severity of this defect was found with progression of the disease and was most pronounced in patients with skin anergy and absolute lymphopenia. The marked abnormality observed in patients restudied after intensive therapy returned towards normal in patients achieving a long lasting, unmaintained complete remission. The data suggest the early presence of an intrinsic functional lymphocyte defect, increasing severity of which may lead to progressive immunoincompetence, reflected in vitro by impaired lymphocyte responsiveness and in vivo by skin anergy and ultimately lymphopenia.

\section{INTRODUCTION}

Lymphocyte activation by phytohemagglutinin (PHA) ${ }^{1}$ has been extensively studied in patients with Hodgkin's disease in whom a deficit in cell mediated immunity is known to exist (1-4). The conventional single dose maximum PHA stimulation discloses a lymphocyte abnormality on relatively few patients (5-7). Correlation with skin test reactivity, $(5,6,8)$ stage $(5,9,10)$, peripheral blood lymphocyte count, and systemic symptomatology $(5,9,10)$ has shown considerable variation. However, since many studies were conducted on patients during the various phases of their disease and treatment, the inconsistency of these observations may reflect the heterogeneity and insensitivity of the methodology and the timing of the studies as well as the status of these patients' immune competence.

Reccived for publication 31 March 1975 and in revised form 17 Junc 1975.

'Abbreviations used in this paper: PHA, phytohemagglutinin, $\mathrm{PPD}$, purified protein derivative.
We have previously shown that lymphocyte transformation to a wide range of $\mathrm{PHA}$ concentrations, encompassing the entire spectrum of lymphocyte response capabilities (11), is more discriminating than the conventional method of a single dose PHA stimulation. This approach, confirmed by others $(12,13)$, discloses a lymphocyte abnormality in patients with Hodgkin's disease and disseminated solid tumors more readily than the single dose PHA assay.

The present report confirms and extends our previous observations and demonstrates the sensitivity of this approach for detecting an underlying lymphocyte defect in previously untreated patients with Hodgkin's disease. It also examines the quantitative aspects of the various lymphocyte response patterns obtained and their correlation with prognostically valuable clinical parameters and with the ultimate course of the disease.

\section{METHODS}

Paticnts. 35 consecutive, previously untreated patients with Hodgkin's disease were studied. The group consisted of 23 males and 12 females with a mean age of $40 \mathrm{yr}$ (range 4-78). The histologic subtypes were identified according to the Rye modification of the Lukes-Butler classification. There were 5 patients with lymphocyte predominance, 15 with nodular sclerosing, 14 with mixed cellularity, and 1 with lymphocyte depletion. All patients were carefully staged, including lymphangiography, bone marrow biopsy, and exploratory laparotomy with splenectomy, the latter being performed in 17 patients with clinical stages less than III B. Bone and liver scans and lung tomograms were performed as indicated. The distribution of the patients by stages was as follows: I $A=2$, II $A=6$, III $\mathrm{A}=3$, IV $\mathrm{A}=0$, I $\mathrm{B}=0$, II $\mathrm{B}=5$, III $\mathrm{B}=13$, and IV $\mathrm{B}=6$.

Skin testing. All patients were skin tested with the following intradermal recall antigens: purified protein derivative (PPD), mumps antigen, streptokinase-streptodornase, and Candida albicans. Their ability to be sensitized by $2,4-$ dinitrochlorobenzene was also studied. Skin tests were applied and interpreted before laparotomy and therapy.

Lymphocyte separation and cultures. In all cases blood was drawn before staging and therapy. As previously reported (14), 30-35 $\mathrm{ml}$ of heparinized blood (preservative free, Connaught Laboratories, Toronto, Canada), was sedimented with dextran (mol wt 250,000, Sigma Chemical Co.,

The Journal of Clinical Investigation Volume 56 October 1975.951-957 


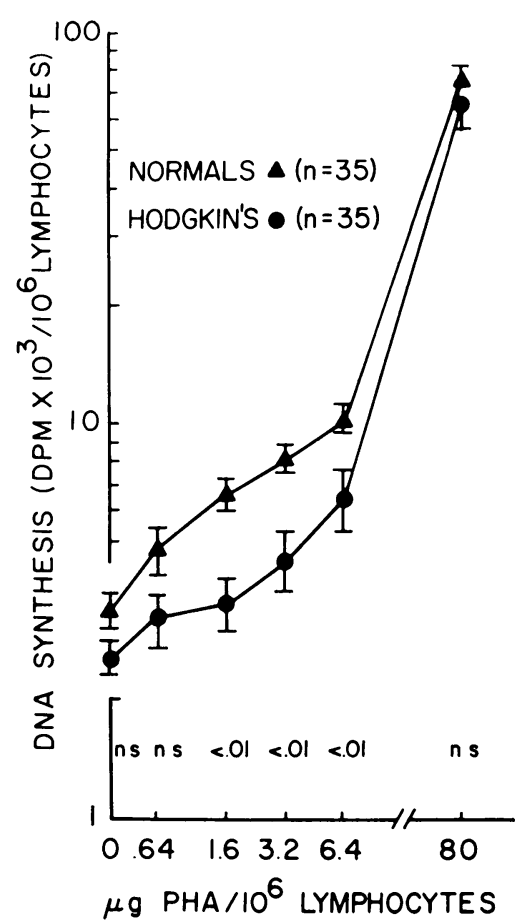

Figure 1 Lymphocyte responsiveness in Hodgkin's and normals. Lymphocyte responsiveness to PHA from normals $(\boldsymbol{\Lambda}, n=35)$ and patients with Hodgkin's disease ( $\bullet$, $n=35)$. The data is expressed as DNA synthesis $/ 10^{\circ}$ lymphocytes and presented as mean $\pm \mathrm{SE}$ for each PHA concentration. Significance of difference $(P$ value $)$ between normals and Hodgkins disease as indicated at each PHA concentration.

St. Louis, Mo.). The buffy coat passed through a glass bead column to yield a lymphocyte suspension which was comparable in normals and patients in terms of lymphocyte purity $(75-95 \%)$ and nonlymphoid cell contamination. Each culture was made of $1 \times 10^{6}$ lymphocytes in a $2-\mathrm{ml}$ volume of minimal essential medium (Gibco, Grand Island Biological Co., Grand Island, N. Y.), $20 \%$ fetal calf serum (Gibco), antibiotics (penicillin $100 \mathrm{U} / \mathrm{ml}$, streptomycin 100 $\mu \mathrm{g} / \mathrm{ml}$, and mycostatin $100 \mathrm{U} / \mathrm{ml}$ ), and the appropriate concentration of PHA. A single batch of PHA-M (no. 562543, Difco Laboratories, Detroit, Mich.) was used throughout the study in doses from 0.64 to $80.0 \mu \mathrm{g}$ PHAprotein (total protein content measured by spectrophotometry, Beckman Instruments Inc., Fullerton, Calif.). This spectrum of PHA concentrations was used after demonstration that in our system less than $0.64 \mu \mathrm{g}$ PHA failed to significantly activate normal lymphocytes, whereas $80 \mu \mathrm{g}$ resulted in maximum lymphocyte responses beyond which deoxyribonucleic acid (DNA) synthesis decreased due to the cytotoxic effect of PHA. After $68 \mathrm{~h}$ incubation at $37^{\circ} \mathrm{C}$, DNA was pulse labeled $(4 \mathrm{~h})$ with $0.5 \mu \mathrm{Ci}$ of tritiated thymidine (New England Nuclear, Boston, Mass., sp act $6.7 \mathrm{Ci} / \mathrm{mmol})$, precipitated with $10 \%$ trichloroacetic acid (TCA) $(\times 2)$, washed with $95 \%$ methanol $(\times 2)$, dissolved in $0.5 \mathrm{ml}$ of Nuclear Chicago Solubilizer, and counted in a toluene-based scintillation fluid. Counts per minute were measured at ambient temperature in an LS150 Beckman spectrometer with a counting efficiency of
$45 \pm 0.9 \%$, calculated according to the external standardization method (15).

The mean and standard error of the three samples at each PHA concentration were calculated. Significant DNA synthesis $(P<0.05)$ was determined by statistical analysis (Student's $t$ test) comparing DNA synthesis from each PHA concentration to the unstimulated controls. The threshold of lymphocyte responsiveness was identified by the minimum stimulatory concentration of PHA capable of eliciting significant DNA synthesis. Maximum lymphocyte transformation was defined by the DNA synthesis of the maximally stimulated cultures.

\section{RESULTS}

Delayed hypersensitivity reactions. 21 patients (60\%) exhibited anergic skin reactions. This does not differ significantly from $55 \%$ found in a large recent study (16). Of the 14 patients who had one or more positive skin test, their response was as follows: 2,4-dinitrochlorobenzene $86 \%$, Candida $79 \%$, streptokinase-streptodornase $36 \%$, mumps $36 \%$, and PPD $21 \%$.

Lymphocyte responsiveness in normal donors. As previously reported, $1.6 \mu \mathrm{g}$ PHA-protein $/ 10^{\circ}$ lymphocytes, which induced significant DNA synthesis over and above that of unstimulated control cultures, represented the least stimulus capable of consistently initiating lymphocyte activation in all normal subjects. Each subsequent increment in PHA concentration invariably resulted in augmented DNA synthesis reaching a maximum in response to $80 \mu \mathrm{g}$ of $\mathrm{PHA}$-protein $/ 10^{6}$ lymphocytes. This PHA dose-response pattern was present in each individual tested. The pooled data can be seen in Fig. 1.

As previously reported (14), the magnitude of DNA synthesis showed considerable intra and interpersonal variation at each PHA concentration tested, however, the threshold of lymphocyte responsiveness and the pattern of PHA dose-response curve elicited remained predictably reproducible.

Lymphocyte responsiveness in the Hodgkin's group. It can be appreciated in Fig. 1 that the shape of the curve from the Hodgkin's group (pooled data) is at variance with that of normals. Although the base line, unstimulated DNA synthesis was not significantly subnormal; these cells were relatively insensitive to low concentrations of $\mathrm{PHA}$, requiring twice more $\mathrm{PHA}$ $(3.2 \mu \mathrm{g})$ than normal to initiate lymphocyte activation. Because of this elevated threshold to PHA stimulation beyond which PHA concentration-dependent rate of DNA synthesis appears to progress normally, the magnitude of DNA synthesis in Hodgkin's lymphocytes was statistically subnormal in response to $1.6,3.2$, and 6.4 $\mu \mathrm{g}$ PHA-protein. However, these cells were capable of a normal response when maximally stimulated, as shown by the magnitude of DNA synthesis elicited by $80 \mu \mathrm{g}$ PHA-protein.

The Hodgkin's population was subdivided according to skin test reactivity, constitutional symptomatology, 


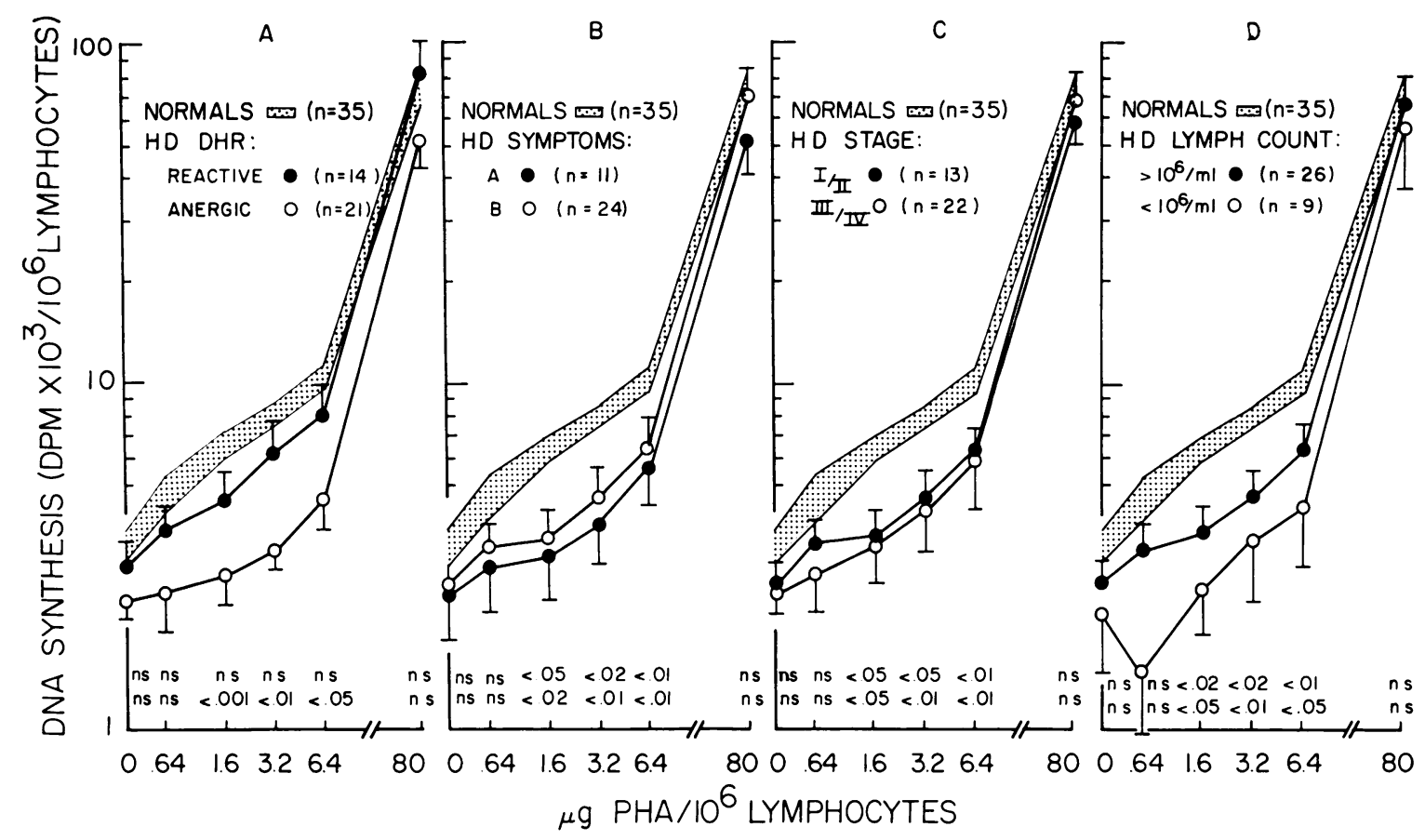

FIgURE 2 Lymphocyte responsiveness in Hodgkin's according to clinical status. Lymphocyte responsiveness to PHA from patients with Hodgkin's disease grouped according to skin tests (A), constitutional symptoms (B), stage of disease (C), and circulating lymphocyte counts (D), as indicated in each panel, are compared to normal responses and presented as mean \pm SE. Significance of difference $(P$ value) between normals and each patient subgroup as indicated at each PHA concentration.

peripheral blood lymphocyte count, and extent of disease. As shown in Fig. 2A, significant differences in lymphocyte responses to PHA were seen between reactive and anergic patients. While patients who reacted to one or more skin tests retained normal responses to PHA, anergic patients were clearly abnormal in the pattern and the magnitude of their responses, reflected by a high threshold for PHA activation with significant subnormal responses to low PHA concentrations, but no impairment in the spontaneous unstimulated DNA synthesis nor in response to maximum PHA stimulation. The presence or absence of constitutional symptomatology, however, had no effect on the pattern or magnitude of lymphocyte responses to PHA, as shown in Fig. 2B. Although patients with advanced disease (stages III and IV) or lymphopenia showed greater impairment of lymphocyte responsiveness than did patients with early stages and noimal lymphocyte count, respectively, these differences were not statistically significant (Fig. 2C and D).

Individual patterns of response in Hodgkin's patients. When lymphocyte responsiveness to PHA stimulation was analyzed for each individual patient, three patterns of response emerged (Fig. 3). Pattern I included nine individuals $(26 \%)$. These patients showed no detectable abnormality. Indeed, unstimulated DNA synthesis, lymphocyte sensitivity to PHA, the magnitude of PHAdependent DNA synthesis, and the pattern of response were indistinguishable from normal. Pattern II included 20 patients $(57 \%)$ who showed lymphocyte insensitivity to low PHA concentrations. Twice as much PHA as normal or more was required to initiate activation of these cells which were capable, however, of a normal response to maximal stimulation ( $80 \mu \mathrm{g}$ PHA). Finally, pattern III was identified in six patients $(17 \%)$ in whom grossly abnormal DNA synthesis was present throughout, including unstimulated cultures. Only in this latter group of patients would an abnormality have been readily detected by using the conventional, single dose maximum lymphocyte transformation assay. In contrast, our approach of investigating the individual threshold for PHA activation discloses lymphocyte insensitivity to PHA in $74 \%$ of patients (patterns II and III), most of whom (pattern II) retain normal response capabilities to maximal stimulation.

When individual patterns of lymphocyte responses to PHA stimulation were correlated with the patient's clinical status (Table I), it was observed that almost all $(91 \%)$ anergic patients exhibited abnormal lymphocyte responses to $\mathrm{PHA}$. In contrast, only $50 \%$ of pa-

Immunocompetence in Hodgkin's Disease 


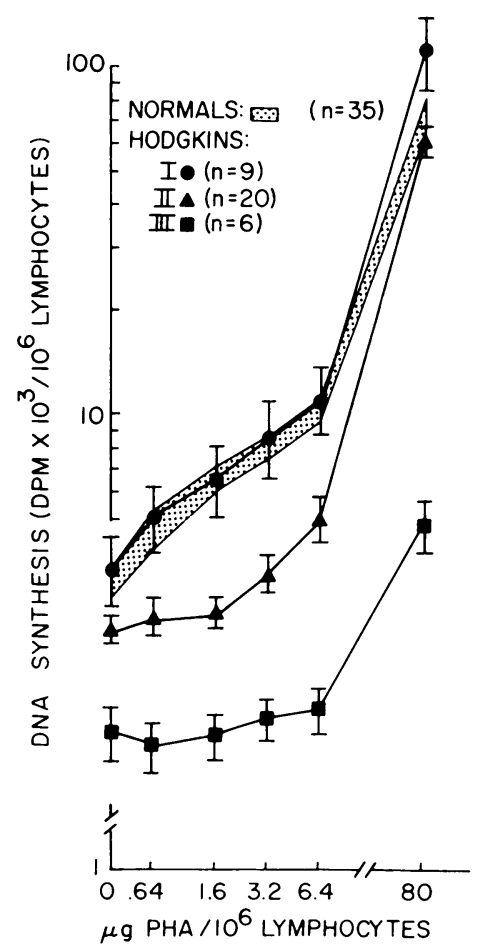

Figure 3 Patterns of lymphocyte responsiveness in Hodgkin's. Hodgkin's disease, expressed as mean $\pm \mathrm{SE}$ for each pattern observed (see text), as compared to normal. Significance of difference ( $P$ value) between normal and pattern I is $N S$, pattern II is $<0.01$ at $1.6,3.2$, and $6.4 \mu \mathrm{g}$ $\mathrm{PHA}$, and pattern III is $<0.001$ at all PHA concentrations.

tients with reactive skin tests showed impaired lymphoblastogenesis and this consisted mostly of the subtle defect associated with pattern II. The presence or absence of consitutional symptoms and the presence of a normal circulating lymphocyte count seemed to exert no influence on the percentage nor the degree of detected lymphocyte abnormality. The effect of lymphopenia on lymphoblastogenesis could not be analyzed separately by virtue of the concomitant anergy exhibited by these patients. Thus, the patterns of response from lymphopenic patients are reminiscent of those observed with anergy alone. An abnormality was detected as frequently in patients with stages I/II $(77 \%)$ as in those with stages III/IV $(73 \%)$. However, patients with early disease exhibited exclusively the subtle lymphocyte abnormality associated with pattern II. The favorable influence of positive skin tests, and to a lesser extent of stages I and II, and conversely the unfavorable influence of anergy upon lymphocyte responsiveness to PHA were observed to predominate over any other clinical parameter or combination thereof.

Lymphocyte responsiveness in previously treated Hodgkin's. The abnormality of lymphocyte responsiveness present in untreated patients was appreciably greater after radiation or combination chemotherapy. Analysis of individual responses (Table II) showed that $24 \%$ of treated patients had a normal dose-response curve (pattern I), 29\% showed lymphocyte insensitivity to submaximal PHA stimulation (pattern II), and $47 \%$ had abnormal responses at all levels of PHA stimulation (pattern III). It is noteworthy that although the overall incidence of lymphocyte abnormality (76\%) is similar to that of previously untreated Hodgkin's $(74 \%)$, contrary to the latter, most of these patients exhibited the greatest degree of lymphocyte abnormality. Interestingly, of eight patients restudied during unmaintained complete remission over a period of 1-7 yr, half exhibited normal lymphocyte responses, the remainder showing mostly the subtle defect of pattern II. All four restudied patients who died in relapse exhibited the greatest lymphocyte abnormality of pattern III.

\section{DISCUSSION}

The marked variation of PHA-induced lymphocyte transformation observed among normals $(14,17)$ and in a given individual upon repeated testing (14) hampers precise definition of normal and abnormal lymphocyte responsiveness to PHA stimulation. The conventional single PHA concentration, aiming at maximal

TABLE I

Patterns of Lymphocyte Responsiveness and Clinical Status*

\begin{tabular}{|c|c|c|c|c|c|c|c|c|c|}
\hline \multirow{2}{*}{$\begin{array}{l}\text { PHA- } \\
\text { response } \\
\text { pattern }\end{array}$} & \multirow[b]{2}{*}{$\begin{array}{c}\text { All HD } \\
(n=35)\end{array}$} & \multicolumn{2}{|c|}{ Skin tests } & \multicolumn{2}{|c|}{ Constitutional symptoms } & \multicolumn{2}{|c|}{ Lymphocyte count } & \multicolumn{2}{|c|}{ Stage } \\
\hline & & $\begin{array}{c}\text { Positive } \\
(n=14)\end{array}$ & $\begin{array}{l}\text { Negative } \\
(n=21)\end{array}$ & $\begin{array}{c}\text { "A" } \\
(n=11)\end{array}$ & $\begin{array}{c}\text { "B" } \\
(n=24)\end{array}$ & $\begin{array}{l}\text { Normal } \\
(n=26)\end{array}$ & $\begin{array}{c}\text { Low } \\
(n=9)\end{array}$ & $\begin{array}{c}\mathrm{I} / \mathrm{II} \\
(n=13)\end{array}$ & $\begin{array}{c}\mathrm{III} / \mathrm{IV} \\
(n=22)\end{array}$ \\
\hline I & 26 & 50 & 9 & 28 & 25 & 30 & 11 & 23 & 27 \\
\hline $\begin{array}{l}\text { II } \\
\text { III }\end{array}$ & $\left.\begin{array}{l}57 \\
17\end{array}\right\} 74 \ddagger$ & $\left.{ }_{7}^{43}\right\} 50 \ddagger$ & $\left.\begin{array}{l}67 \\
24\end{array}\right\} 91 \ddagger$ & $\left.\begin{array}{l}55 \\
18\end{array}\right\} 73 \ddagger$ & $\left.\begin{array}{l}58 \\
17\end{array}\right\} 75 \ddagger$ & $\left.\begin{array}{l}58 \\
12\end{array}\right\} 70 \ddagger$ & $\left.\begin{array}{l}56 \\
33\end{array}\right\} 89 \ddagger$ & ${ }_{0}^{77} 77 \ddagger$ & $\left.\begin{array}{l}46 \\
27\end{array}\right\} 73 \ddagger$ \\
\hline
\end{tabular}

* Percentage distribution of lymphocyte responsiveness to PHA in patients with Hodgkin's disease according to patterns of response and grouped according to clinical status as indicated in each panel.

$\ddagger$ Indicates total abnormality detected in each subgroup of patients.

HD, Hodgkin's disease. 
TABLE II

l'allerns of Lymphocyle Responsizeness and Discuse .Silulus*

\begin{tabular}{ccccc}
\hline $\begin{array}{c}\text { PHA-response } \\
\text { patterns }\end{array}$ & $\begin{array}{c}\text { Pre- } \\
\text { therapy } \\
(n=35)\end{array}$ & $\begin{array}{c}\text { Post- } \\
\text { therapy } \\
(n=17)\end{array}$ & $\begin{array}{c}\text { Complete } \\
\text { remission } \\
(n=8)\end{array}$ & $\begin{array}{c}\text { Dead } \\
(n=4)\end{array}$ \\
\hline I & 26 & 24 & 50 & 0 \\
II & 57 \\
III & $17\} 7\}^{\ddagger}$ & $\left.\begin{array}{l}29 \\
47\end{array}\right\} 76 \ddagger$ & 38 \\
\end{tabular}

* Percentage distribution of lymphocyte responsiveness to PHA in patients with Hodgkin's disease according to patterns of response and grouped as indicated in each panel.

$\ddagger$ Indicates total abnormality detected in each subgroup of patients.

lymphocyte stimulation, discloses impaired PHA transformation in only $20-40 \%$ of patients with Hodgkin's disease (5-7). Furthermore, the generally poor correlation between lymphoblastogenesis and delayed hypersensitivity reactions in the cell donor before (7) and after therapy $(5,6,9,10)$ suggests that the conventional transformation assay does not reliably reflect the status of immune competence $(6,18)$. Although still controversial $(6,18)$, the discrepancies of these observations may reflect the quantitative rather than qualitative nature of immune phenomena: powerful stimulation (by maximum concentrations of mitogens, antigens or HL-A [19]) may overcome an underlying subtle lymphocyte defect, disclosed only by de-escalating the intensity of the stimulus, whether in vitro (11) or in vivo (16). The present study confirms and extends our previous observations of a subtle lymphocyte defect in most patients with previously untreated Hodgkin's disease, utilizing the PHA dilution technique. It differs from other published reports $(5-10,12,13,20)$ in two important aspects. First, the three distinct patterns of PHA response observed in Hodgkin's disease identified patients with severe $(17 \%)$, mild $(57 \%)$, and lack of $(26 \%)$ in vitro abnormality, thus permitting quantitative estimation of the lymphocyte function. Secondly, we have correlated the magnitude of the observed lymphocyte defect with prognostically valuable clinical parameters in each individual. A direct relationship was noted with skin reactivity, absolute lymphocyte count, and extent of the disease. The severity of in vitro defect increased with progression of the disease. However, the demonstration of defective lymphocyte function in patients with stage I/II, normal skin tests, and lymphocyte count, and its independence from constitutional symptoms, suggest this defect to be inherent to the disease and not a reflection of its complications.

It is disturbing that the conventional PHA transformation assay and skin test reactivity have no prognostic value $(6,7,21)$. Although the availability of effective therapy may mask any possible contribution by the immune system (7), such findings may reflect the insensitivity of the qualitative tests routinely utilized in assessing the integrity of the immune system. It is of interest, however, that PPD negative patients after Calmette-Guerin bacillus (BCG) vaccination exhibited greatly shortened survival when compared to reactive individuals (22). The return to normal PHA transformation after prolonged unmaintained remissions observed in this and other studies $(6,8,10)$ may be due to the reappearance of cells depleated during active disease. The relationship of this phenomenon to improving immunocompetence is supported by the reappearance of reactive skin tests during unmaintained remission $(3,23)$.

Although the nonpurified PHA utilized in this study contains nonmitogenic protein contaminants, we have obtained similar results using PHA-M from two different sources, PHA-P as well as a pure PHA fraction. It is of interest that the last six patients of the present series were concomitantly studied with a highly pure, single mitogenic fraction of PHA with similar quantitative results. A similar functional abnormality has also been described in Hodgkin's lymphocytes stimulated with pure PHA and evaluated by their RNA synthesis capabilities (13). However, quantitation of the defect was not attempted and no correlation was found with symptomatology, skin reactivity, and absolute lymphocyte count. Another sensitive approach is the study of the entire time-course of the PHA response (20) that disclosed abnormal Hodgkin's lymphocyte responses in all patients studied. However, the in vitro abnormality observed over an 8-day incubation period may reflect magnified in vitro cell death as much as refractoriness to mitogenic stimulation. In that study no quantitation of the lymphocyte impairment was attemped and no clinical correlations were offered.

Several possible mechanisms could be implicated in the impaired PHA response seen in Hodgkin's disease: (a) Laboratory artifacts seem unlikely by virtue of the predictability of responses in normals, the dose-dependence of transformation observed in normals and responders, and the reproducibility of replicate cultures (14). (b) Serum factors reportedly diminish the PHA response of otherwise PHA-responsive cells $(8,24,25)$. However, the failure of Hodgkin's serum to diminish normal lymphocyte responsiveness to PHA (26) and the persistence of the Hodgkin's lymphocyte defect after removal of autologous plasma $(8,27)$ argue against the role of serum factors in the functional lymphocyte abnormality reported here. (c) Removal of "helper cells" during the lymphocyte separation procedure (28, 29). This is unlikely by virtue of the similar cell recovery, purity, and degree of nonlymphoid cell contamination of the final lymphocyte suspensions obtained from both patients and controls. Moreover, highly pure 
lymphocyte suspensions have elicited similar results (20). (d) An intrinsic functional abnormality of all PHA-responsive lymphocytes or depletion of these cells $(11,20)$. Dilution of T-lymphocytes by chronic lymphatic leukemia cells seems to account for the abnormal PHA transformation seen in this disease (30). Similarly, the impaired lymphoblastogenesis observed in Hodgkin's may represent normal response by cells depleted of a certain T-cell subpopulation, as recently described (31). However, some of our patients with impaired PHA transformation exhibited normal $\mathrm{T}$ - and B-cell population ratios.

The various patterns of Hodgkin's lymphocytes response to PHA shown in the present study suggest the presence of two abnormalities: the first represents quantifiable lymphocyte insensitivity to PHA stimulation. Although the nature of this lymphocyte defect has not been elucidated, recent work in our laboratory (32) has demonstrated quantitatively and qualitatively normal binding of pure ${ }^{125} \mathrm{I}-\mathrm{PHA}$ to Hodgkin's lymphocytes. These cells, however, exhibited increased thresholds for PHA activation and were hyporesponsive to normally bound PHA, thus suggesting a functional metabolic cell defect located beyond membrane receptor sites; the second, reflected in the markedly different shape of pattern III (with significantly subnormal spontaneous DNA synthesis), may relate to an endogenous qualitative defect superimposed to the qualitative lymphocyte insensitivity to PHA. This combined defect may reflect in vitro cell death $(5,6,8)$ or it may relate to in vivo stimulation leading to PHA refractory T-lymphocytes $(11,20)$, loss of these cells recirculating capacity (33), or their depletion from peripheral blood $(11,20,31)$. Although the direct relationship shown in this report between spontaneous and PHA-induced DNA synthesis in Hodgkin's disease favors the former concept, the presence of "large lymphoid cells" engaged in DNA synthesis found in Hodgkin's blood (34) and the recent discovery of Hodgkin's disease tumor-associated antigens (35) provide a strong basis for the latter. It is conceivable that these two phenomena are related, and patients with pattern III may be at the end of a spectrum of patients with gradually increasing functional lymphocyte abnormality.

Our findings of a functional lymphocyte defect in most patients with localized disease, which is intensified as the disease progresses, with the most profound impairment found in anergic, lymphopenic patients with advanced disease suggest the following hypothesis: an intrinsic functional lymphocyte abnormality inherent to Hodgkin's, possibly reflecting in vivo stimulation of these cells by Hodgkin's tumor-specific antigens, would develop early in the course of the disease. With disease progression, this initially subtle (and therefore elusive) impairment becomes more pronounced leading to pro- gressive immunoincompetence with loss of immunologic memory $(16,21)$, shortened cell survival reflected by in vitro cell death $(5,6,8)$, and in vivo cell depletion $(11,20,31)$, with ensuing lymphopenia found mostly in far advanced disease (36).

This study was not intended to establish the prognostic usefulness of the impaired PHA response observed in Hodgkin's disease. However, if cellular immune mechanisms constitute the main determinant of host resistance in this disease (22), quantitative evaluation of immunocompetence, as illustrated in this report, may eventually be of paramount importance to the clinician in following the course of the disease and the adequacy of treatment. Such a goal will require new techniques of greater sensitivity and specificity.

\section{ACKNOWLEDGMENTS}

The author is indebted to Mrs. J. Agee for excellent technical assistance.

\section{REFERENCES}

1. Schier, W. W., A. Roth, G. Ostroff, and M. H. Schrift. 1956. Hodgkin's disease and immunity. Am. J. Med. 20: 94-99.

2. Kelley, W. D., D. L. Lamb, R. L. Varco, and R. A. Good. 1960. An investigation of Hodgkin's disease with respect to the problem of homotransplantation. Ann. N. Y. Acad. Sci. 87: 187-202.

3. Aisenberg, A. C. 1962. Studies on delayed hypersensitivity in Hodgkin's disease. J. Clin. Invest. 41: 19641970.

4. Aisenberg, A. C. 1966. Immunologic status of Hodgkin's disease. Cancer. 19: 385-394.

5. Brown, R. S., H. T. Haynes, H. F. Foley, H. A. Godwin, C. W. Berard, and P. P. Carbone. 1967. Hodgkin's disease. Immunologic, clinical, and histologic features of 50 untreated patients. Ann. Intern. Med. 67: 291-302.

6. Han, T., and J. E. Sokal. 1970. Lymphocyte response to phytohemagglutinin in Hodgkin's disease. Am. J. Med. 48: 728-734.

7. Corder, M. P., R. C. Young, R. S. Brown, and V. T. DeVita. 1972. Phytohemagglutinin-induced lymphocyte transformation: the relationship to prognosis of Hodgkin's disease. Blood J. Hematol. 39: 595-601.

8. Trubowitz, S., B. Masek, and A. Del Rosario. 1966. Lymphocyte response to phytohemagglutinin in Hodgkin's disease, lymphatic leukemia, and lymphosarcoma. Cancer. 19: 2019-2023.

9. Hersh, E. M., and J. J. Oppenheim. 1965. Impaired in vitro lymphocyte transformation in Hodgkin's disease. N. Engl. J. Med. 273: 1006-1012.

10. Jackson, S. M., J. V. Garrett, and A. W. Craig. 1970. Lymphocyte transformation changes during the clinical course of Hodgkin's disease. Cancer. 25: 843-850.

11. Faguet, G. B., S. P. Balcerzak, and A. F. LoBuglio. 1973. Lymphocyte sensitivity and cellular immunity in neoplasia. Biomedicine (Paris). 19: 43-47.

12. Ziegler, J. B., P. Hansen, and R. Penny. 1973. Defective lymphocyte response to phytohemagglutinin in untreated Hodgkin's disease. Blood J. Hematol. 42: 1026. (Abstr.)

13. Levy, R., and H. S. Kaplan. 1974. Impaired lymphocyte function in untreated Hodgkin's disease. N. Engl. J. Med. 290: 181-186. 
14. Faguet, G. B. 1974. Lymphocyte responsiveness to phytohemagglutinin (PHA): quantitative aspects and reproducibility. J. Reticuloendothel. Soc. 16: 114-121.

15. Cavanaugh, R. 1970. Statistical considerations in external standardization. In The Current Status of Liquid Scintillation Counting. E. D. Bransome, Jr., editor. Grune and Stratton Inc., New York. 293-304.

16. Eltringham, J. R., and H. S. Kaplan. 1973. Impaired delayed hypersensitivity responses in 154 patients with untreated Hodgkin's disease. Natl. Cancer Inst. Monogr. 36: $107-115$.

17. McIntyre, O. R., and A. F. Cole. 1969. Variation in the response of normal lymphocytes to PHA. Int. Arch. Allergy Appl. Immunol. 35: 105-118.

18. Heine, K. M., and H. Stobbe. 1967. Untersuchungen zur Immunokompetenz der Lymphozyten bei lymphoreticularem Erkrankungen. Allerg. Asthma. 13: 103-106.

19. Lang, J. M., Oberling, F., M. M. Tongio, S. Mayer, and R. Waitz. 1972. Mixed lymphocyte reactions as assay for immunological competence of lymphocytes from patients with Hodgkin's disease. Lancet. 1: 1261-1263.

20. Matchett, K. M., A. T. Huang, and W. B. Kremer. 1973. Impaired lymphocyte transformation in Hodgkin's disease. Evidence for depletion of circulating T-lymphocytes. J. Clin. Invest. 52: 1908-1917.

21. Young, R. C., M. P. Corder, H. A. Haynes, and V. T. DeVita. 1972. Delayed hypersensitivity in Hodgkin's disease. A study of 103 untreated patients. Am. J.Med. 52: $63-72$.

22. Sokal, J. E., and C. W. Aungst. 1969. Respense to BCG vaccination and survival in advanced Hodgkin's disease. Cancer. $24:$ 128-134.

23. Sokal, J. E., and N. Primikirios. 1961. The delayed skin test response in Hodgkin's disease and lymphosarcoma. Effect of disease activity. Canccr. 14: 597-607.

24. Newberry, W. M., J. W. Shorey. J. P. Sanford, and B. Combes. 1973. Depression of lymphocyte reactivity to phytohemagglutinin in serum from patients with liver disease. Cell Immunol. 6: 87-97.

25. Newberry, W. M., and H. P. Sanford. 1971. Defective cellular immunity in renal failure: depression of reactivity of lymphocytes to phytohemagglutinin by renal failure serum. J. Clin. Invest. 50: 1262-1271.

26. Han, T. 1972. Effect of sera from patients with Hodgkin's disease on normal lymphocyte response to phytohemagglutinin. Cancer. 29: 1626-1631.

27. Hersh, E. M., and W. S. Irvin. 1969. Blastogenic responses of lymphocytes from patients with untreated and treated lymphomas. Lymphology. 2: 150-160.

28. Hersh, E. M., and J. E. Harris. 1968. Macrophagelymphocyte interaction in the antigen-induced blastogenic response of human peripheral blood leukocytes. J. Immunol. 100 : 1184-1194.

29. Yachnin, S., L. W. Allen, J. M. Baron, and R. H. Svenson. 1972. The potentiation of phytohemagglutinin-induced lymphocyte transformation by cell-cell interaction; a matrix hypothesis. Cell Immunol. 3: 569-589.

30. Wybran, J., S. Chantler, and H. H. Fudenberg. 1973. Isolation of normal T-cells in chronic lymphatic leukaemia. Lancet. 1: 126-129.

31. Aiuti, F., and H. Wigzell. 1973. Function and distribution pattern of human T lymphocytes. II. Presence of $T$ lymphocytes in normal humans and in humans with various immunodeficiency disorders. Clin. Exp. Immunol. 13 : 183-189.

32. Faguet, G. B. 1974. Membrane events that precede lymphocyte activation by phytohemagglutinin (PHA) in normals and Hodgkin's. Blood J. Hematol. 44: 920. (Abstr.)

33. Jacobsson, H., and H. Blomgren. 1973. Evidence for a loss of recirculating capacity of $\mathrm{T}$-cells after antigenic stimulation. Clin. Exp. Immunol. 13: 439-453.

34. Crowther, D., G. H. Fairley, and R. L. Sewell. 1969. Significance of the changes in the circulating lymphoid cells in Hodgkin's disease. Br. Med. J. $2:$ 473-477.

35. Order, S. E., M. Porter, and S. Hellman. 1971. Hodgkin's disease: evidence for a tumor-associated antigen. N. Engl. J. Med. 285: 471-474.

36. Aisenberg, A. C. 1965. Lymphocytopenia in Hodgkin's disease. Blood J. Hematol. 25 : 1037-1042. 